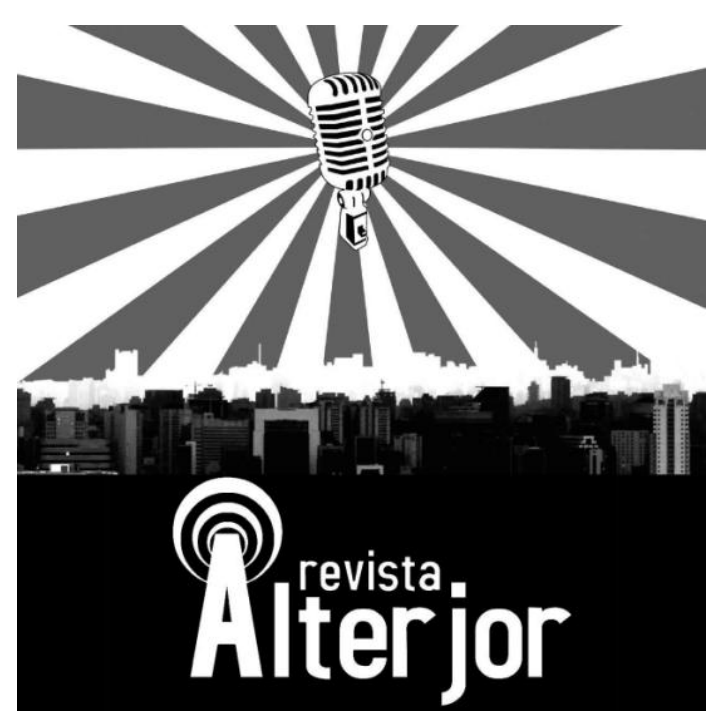

\title{
COMUNICAÇÃO ORGANIZACIONAL: UMA FERRAMENTA ESTRATÉGICA DE COMPATIBILIZAÇÃO DE INTERESSES
}

\author{
Edwaldo Costa ${ }^{1}$
}

Taise da Silva Oliveira ${ }^{2}$

\begin{abstract}
RESUMO: O objetivo deste artigo foi mostrar a importância do uso estratégico da comunicação organizacional, com foco no ambiente interno, e as visões atuais impulsionadas pelas possibilidades tecnológicas, avaliando como ela pode ser uma ferramenta para a compatibilização dos interesses dos empregados e da empresa. A metodologia adotada é de abordagem bibliográfica qualitativa. Concluiu-se que é mediante um olhar para os sujeitos como seres completos e imbuídos de uma cultura particular, considerando o respeito à diversidade de perspectivas, que se torna possível otimizar a resolução de problemas dentro das organizações e compatibilizar os interesses.
\end{abstract}

PALAVRAS-CHAVE: Estratégias organizacionais. Comunicação integrada. Sistema comunicacional.

ABSTRACT: The objective of this article was to show the importance of the strategic use of organizational communication, focusing on the internal environment, and the current views driven by technological possibilities, evaluating how it can be a tool for reconciling the interests of employees and the company. The methodology adopted is a qualitative bibliographic approach. It was concluded that it is through looking at the subjects as complete beings and imbued with a particular culture, considering respect for the diversity of perspectives, that it becomes possible to optimize the resolution of problems within organizations and to harmonize interests.

KEYWORDS: Organizational strategies. Integrated communication. Communication system.

\footnotetext{
${ }^{1}$ Pós-Doutor em Comunicação pela Universidade de São Paulo (ECA/USP) e jornalista do Centro de Comunicação Social da Marinha do Brasil. E-mail: edwaldocosta1@gmail.com

${ }^{2}$ Pós-Graduada em Administração de Marketing e Comunicação Empresarial pela Universidade Veiga de Almeida e assessora de comunicação no Comando do Pessoal de Fuzileiros Navais da Marinha do Brasil. E-mail: taise.oliveir@hotmail.com
}

Revista ALTERJOR

Grupo de Estudos Alterjor:Jornalismo Popular e Alternativo (ECA-USP)

Ano 10 Volume 02 Edição $22 \quad$ Juhlo-Dezembro de 2020

Avenida Professor Lúcio Martins Rodriģues, 443, Cidade Universitária, São Paulo, CEP: 05508-020 


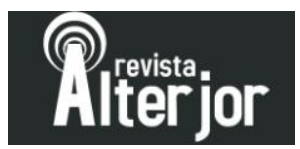

\section{INTRODUÇÃO}

Como a comunicação organizacional pode ser utilizada como ferramenta para a compatibilização dos interesses dos empregados e da empresa?

A palavra comunicação é palavra derivada do latim communicare, e significa tornar comum, partilhar, conferenciar. "Comunicar implica participação em interação, em troca de mensagens, em emissão ou recebimento de informações novas" (RABAÇA; BARBOSA, 1987, p. 155-6). Nesse sentido, Molena (2009, p. 5) afirma que "a Comunicação não é uma simples troca de mensagens. Exige a construção de um relacionamento. É necessário que o emissor queira se comunicar. Que transmita uma mensagem, escrita, falada, ou outro tipo. O receptor tem que querer receber a mensagem".

Por sua vez, organização advém da origem grega organon, que significa instrumento, órgão ou aquilo que se trabalha, um sistema para atingir os resultados pretendidos. De acordo, com Chiavenato (2005, p. 24) "organização é uma unidade social conscientemente coordenada, composta de duas ou mais pessoas, que funciona de maneira relativamente contínua, com o intuito de atingir um objetivo comum". No Brasil, o termo muitas vezes é utilizado como sinônimo para empresa ou instituição.

Os caminhos da comunicação organizacional atualizados e direcionados a novos olhares estratégicos exige uma necessidade de pensarmos as possibilidades de compreensão acerca da comunicação organizacional e de revisitar a própria comunicação nas múltiplas dimensões que adquire no cenário empresarial. Diante disso, o objetivo deste artigo é, partindo de uma metodologia de abordagem bibliográfica qualitativa, mostrar a importância do uso estratégico da comunicação organizacional, com foco no ambiente interno, e as visões atuais impulsionadas pelas possibilidades tecnológicas, avaliando como ela pode ser uma ferramenta para a compatibilização dos interesses dos empregados e da empresa. 


\section{Anteijor}

\section{A COMUNICAÇÃO ORGANIZACIONAL}

Somando os conceitos de comunicação e organização, com base em Ribeiro (2008), a comunicação organizacional é uma componente fundamental para a eficiência e eficácia, sendo que a eficácia é considerada a capacidade de um indivíduo para produzir resultados responsavelmente, e a eficiência é a capacidade potencial que têm os sistemas, simples ou complexos, para produzir resultados.

A Comunicação organizacional, segundo Margarida Kunsch (2002), estuda como se processa o fenômeno comunicacional dentro das organizações no âmbito da sociedade global. Além disso, ela analisa o sistema, o funcionamento e o processo de comunicação entre a organização e seus diversos públicos; configura as diferentes modalidades comunicacionais que permeiam sua atividade, formando o composto da Comunicação Integrada, que se compartimenta em Comunicação institucional, Comunicação mercadológica, Comunicação interna e Comunicação administrativa. Nesse contexto,

o sistema organizacional se viabiliza graças ao sistema de comunicação nele existente, que permitirá sua contínua realimentação e sua sobrevivência. Caso contrário, entrará num processo de entropia e morte. Daí a imprescindibilidade da comunicação para uma organização social (KUNSCH, 2002, p. 69).

O composto da comunicação integrada citado por Kunsch (2002) abarca os diversos públicos de uma organização, os internos, mistos e externos. Conforme sua definição, esse composto é a

Filosofia que direciona a convergência das diversas áreas, permitindo uma atuação sinérgica. Pressupõe-se uma junção da comunicação institucional, da comunicação mercadológica, da comunicação interna e da comunicação administrativa, que formam o mix, o composto da comunicação organizacional (KUNSCH, 2002, p. 150).

O sistema comunicacional é fundamental para o processamento das funções administrativas internas e do relacionamento das organizações com o meio externo, os aspectos relacionais. A comunicação organizacional tem que ser pensada no contexto da 
dinâmica da história contemporânea. Só o fato de a comunicação ser formalizada e sistematizada não é o bastante. É necessário, pois, estudar todos os fenômenos intrínsecos e extrínsecos do que constitui as organizações, a análise de ambiente (KUNSCH, 2002). Nessa mesma linha de raciocínio, deve-se ter em mente que

os homens fazem coisas e atuam muitas vezes "condicionados" pelos seus sistemas biológicos, pela natureza ou pelo poder econômico ou pelo medo, mas diferentemente da sociedade das formigas se comunicam por meio da linguagem, acham e imaginam alternativas, observam e interpretam o mundo e desenvolvem estratégias de ação (VIZER, 2011, p. 69; apud MOURÃO, 2013, p. 6).

Ainda segundo Kunsch (2002), a comunicação administrativa é aquela que se processa dentro da organização, no âmbito das funções administrativas, é o que permite viabilizar todo o sistema organizacional, por meio de uma confluência de fluxos e redes. A comunicação interna é uma ferramenta estratégica para compatibilização dos interesses dos empregados e da empresa, por meio do estímulo ao diálogo, à troca de informações e de experiências e à participação de todos os níveis. Por esse diálogo, o indivíduo, antes de ser um empregado, é um ser humano, um cidadão que merece ser respeitado e considerado. A comunicação interna deve contribuir para o exercício da cidadania e para a valorização do homem. Para a organização, o público interno é um público multiplicador. Na sua família e no seu convívio profissional e social, o empregado será um porta-voz da organização, de forma positiva ou negativa.

Em foco com o mercado e o público externo, a comunicação mercadológica se apresenta tendo em vista a divulgação publicitária dos produtos ou serviços de uma empresa. Está vinculada diretamente ao marketing de negócios, constituindo-se em uma mensagem persuasiva elaborada a partir do quadro sociocultural do consumidor-alvo e dos canais que lhes servem de acesso, utilizando-se das mais variadas formas para atingir os objetivos sistematizados no plano de comunicação da empresa (KUNSCH, 2002).

Finalizando o composto, a Comunicação Institucional é a responsável pela construção e formatação de uma imagem e identidade corporativas fortes e positivas de uma organização. Está intrinsecamente ligada aos aspectos corporativos institucionais 


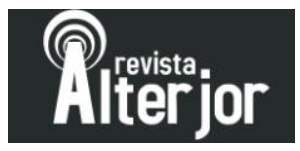

que explicitam o lado público das organizações, constrói uma personalidade creditiva organizacional e tem como proposta básica a influência político-social na sociedade onde está inserida. Portanto, os significados e os relacionamentos que embasam a realidade empresarial são compartilhados com a sociedade e, principalmente, com os públicos mais afetados pela rotina produtiva. Assim, a comunicação, no meio empresarial, deve ser estrategicamente pensada para propagar os valores e a cultura da empresa, sua missão e visão de futuro e, ainda, multiplicar formadores de opiniões, que conferem legitimidade e prestígio às organizações. Com isso, entende-se que uma organização não está isolada, como em uma ilha, à parte dos acontecimentos ao redor. Os acontecimentos externos influenciam e são influenciados pela organização (KUNSCH, 2002).

Ademais, devemos ter em mente que as comunicações nas empresas se processam por meio de duas posições apontadas por Torquato (2015): a comunicação pessoal, que agrupa os comportamentos comunicativos dos indivíduos; e a comunicação estrutural, que congrega as formas de comunicação ligadas às exigências da estrutura funcional da empresa. Isso significa que o universo organizacional constitui em um espaço relacional e complexo. Suas dimensões comunicacionais assumem ainda mais importância quando os indivíduos estabelecem vínculos e relações de interdependência com a estrutura empresarial. Ademais,

\begin{abstract}
a comunicação torna-se um dos papéis ou capacidades do planejamento para que todos na organização - e aqueles públicos externos que a interessam conheçam sua estratégia e posicionamento. Internamente, a comunicação, enquanto um papel do planejamento, também é imprescindível: por meio dela, os empregados sabem o que precisam fazer para que as intenções estratégicas sejam concretizadas (MOURÃO, 2013, p. 4).
\end{abstract}

Nesse sentido, Mourão (2013, p. 5) afirma que os "estudos mais recentes da comunicação - especialmente das últimas três décadas - têm se deslocado da perspectiva informacional para a interacional, colocando a comunicação como estruturadora do novo cenário organizacional". A comunicação passa, então, a ser entendida como estratégia e, de acordo com Reis, Marchiroi e Casali (2010, p. 172), "sob a ótica contemporânea, vislumbra-se a estratégia como processo de produção de 


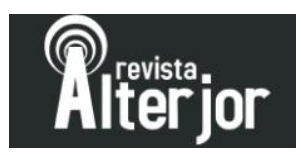

sentindo sobre o presente, que nos diz e nos faz refletir sobre qual é o futuro que estamos construindo com as nossas escolhas”. Segundo indica Mourão (2013, p. 3), "estratégia tanto pode ser um plano, como um padrão, uma posição ou uma perspectiva e o planejamento pode ser compreendido como o processo de elaboração da estratégia".

Além disso, Mourão (2013, p. 6-7) aponta que

a estratégia - dentre elas a de comunicação - pode ser compreendida a partir de sete dimensões: a) estratégia como antecipação, b) decisão, c) método, d) posição, e) marco de referência, f) perspectiva e g) relação com o entorno. Pode-se inferir que essa nova forma de compreender a estratégia de comunicação - que pode ou não ser planejada - vai ao encontro desse novo mundo dinâmico no qual nos inserimos

Bueno (2003) acrescenta que a partir de 1990, a comunicação organizacional se desenvolveu a tal ponto que passou a ser vista de forma estratégica para as empresas, ou seja, se tornou peça chave para os negócios. A comunicação é um poderoso instrumento para integrar e motivar profissionais, conectando-os aos valores que compõem a cultura. É preciso ajustá-la e moldá-la ao público-alvo, estudar todos os fenômenos intrínsecos e extrínsecos que formam a organização, realizar a análise do ambiente organizacional.

Segundo Kunsch (2002), há elementos que são relevantes no processo comunicativo nas organizações, como as barreiras, os níveis de análise, as redes, os fluxos e os meios. As barreiras compõem como exemplo questões pessoais (como comportamento de cada indivíduo); administrativas e burocráticas (forma da organização de atuar e processar as informações); excesso e sobrecarga de informações e informações incompletas e imparciais. Os níveis de análise são o intrapessoal (do indivíduo com ele mesmo); o interpessoal (do indivíduo em contato com outro); o organizacional (da organização com o indivíduo) e o tecnológico (fornecido por meios de comunicação). As redes são as formais (oficiais, transmitidas pela organização, de fontes confiáveis) e informais (originadas de manifestações espontâneas da coletividade). Como declara Torquato (2015, p. 55): "Não se deve combater nem ignorar a rede informal porque a oposição pode apenas encorajar o informal contra o formal. Indica-se, como sugestão viável, a utilização da rede informal sobre o sistema formal". 


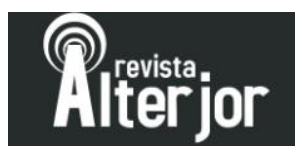

Os fluxos correm em sentidos que se complementam. Os descendentes ou verticais percorrem no sentido do fluxo hierárquico, de cima para baixo, ou seja, dos cargos superiores na hierarquia para os cargos subalternos. Do gerente geral para o subgerente de um determinado setor. Ou de um subgerente para um operário. É a comunicação oficial. No fluxo ascendente ocorre exatamente o contrário da comunicação vertical. O fluxo parte dos estratos subalternos na hierarquia em direção aos estratos superiores, na cúpula. Os colaboradores passaram ao papel de emissores, remetendo demandas ou mesmo elogios e sugestões. Ouvir o público interno é oportunizar o diálogo com quem faz a organização acontecer. A comunicação horizontal ou lateral ocorre entre pares lotados em um mesmo nível hierárquico. Como o nome sugere, ocorre no mesmo nível, como entre dois subgerentes, ou dois operários, ou, ainda, dois diretores gerais. O fluxo transversal, também conhecido por fluxo longitudinal, é marcado pelas diversas direções às quais as mensagens podem percorrer, independentemente da hierarquia vigente na organização (TORQUATO, 2015).

Ou seja, o fluxo da mensagem não precisa corresponder à hierarquia. É mais comum em organizações flexíveis, que prezam a gestão participativa e integrada, ao facilitar o acesso de qualquer colaborador à voz, em qualquer direção. Assim como no fluxo transversal, o circular é comum em organizações pequenas e informais, nas quais um organograma rígido construtor de uma hierarquia nitidamente observável não faz sentido. Quanto maior a aproximação interpessoal, maior tenderá a ser a comunicação entre as partes. Como aponta Torquato $(2015$, p. 8$)$ :

\begin{abstract}
A comunicação exerce um poder expressivo no âmbito das empresas e instituições. Trata-se de um campo que pavimenta a legitimidade e credibilidade das organizações em seus públicos interno e externo e complementa a tipologia dos poderes que são inerentes: remunerativo, coercitivo e normativo.
\end{abstract}

No cenário atual, a gestão da comunicação está fortemente ligada à execução das estratégias e, como consequência, vinculada ao crescimento das organizações. Avaliando o novo ritmo de transformações, intenso e acelerado, gerando relações cada vez mais complexas, pode-se afirmar que as organizações precisam buscar novos 


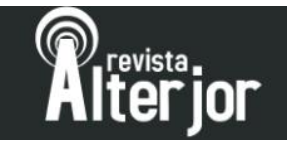

formatos de gestão. Os novos modelos de gestão exigem uma postura diferenciada nos relacionamentos da empresa com colaboradores e com a comunidade, adotando a transparência, com base em valores éticos e gestão socialmente responsável. Bueno (2003, p. 311) acrescenta que

uma política de comunicação funda-se, especialmente, em alguns pressupostos básicos, como o vínculo obrigatório entre comunicação e processo de gestão, entre comunicação e cultura organizacional, a existência de uma estrutura profissionalizada de comunicação e de recursos (humanos, financeiros, tecnológicos e outros) para sua implementação e a vontade política para colocá-la em prática e exigir seu cumprimento.

Atualmente, vivemos na era do capitalismo informacional, segundo definição de Castells (1999). Na era da informação, quando prevalecem organizações em rede, com equipe multidisciplinar, é interessante salientar que os colaboradores precisam estar bem informados, comunicar-se adequadamente de forma a potencializar a força do grupo, estarem alinhados aos processos e objetivos da empresa.

É a quebra realizada pelo mundo contemporâneo. A passagem de uma teoria Clássica, mecanicista, firmada pela Revolução Industrial quando os homens eram vistos e tratados apenas como parte técnica da fábrica, componente ferramental, como retratado no filme Tempos Modernos, de Charles Chaplin. Se antes os teóricos não davam atenção aos aspetos humanos das empresas, hoje eles reconhecem a importância de uma liderança, da benevolência, da equidade e de iniciativas que tornem o ambiente organizacional mais produtivo e agradável. As falhas da produtividade das organizações não são mais apenas problemas técnicos (MORGAN, 1996). Chiavenato (2002) afirma que a tendência atual é a de que os colaboradores de todos os níveis das organizações atuem como administradores e não somente como executores de ordens ou tarefas. Cada colaborador precisa estar consciente de que é um elemento do diagnóstico dos problemas e também um elemento para soluções onde trabalha. Isso faz com as organizações cresçam.

Por sua parte, Bueno (2003, p. 8) declara que 
ao debruçar-se sobre nova realidade, a comunicação Empresarial rompe as fronteiras tradicionais que a identificavam nas décadas anteriores, deixando de ser um mero apêndice do processo de gestão, algo que se descartava ao despontar da primeira crise. Hoje, encontram-se na linha de frente, situada em posição de destaque no organograma, promovendo conhecimento e estratégias para que as empresas e entidades não apenas superem os conflitos existentes, mas possam atuar preventivamente, impedindo que eles se manifestem.

Nesse sentido, tornou-se necessário programar uma nova concepção das relações humanas no trabalho, para que os colaboradores/trabalhadores pudessem começar a ser guiados por um sistema social e a não fossem mais reduzidos a meras unidades caracterizáveis por comportamentos simples e mecânicos (PANTOJA; et al., 2013).

Desta forma, a comunicação surge como uma ferramenta essencial para o desempenho macro e global de uma organização, resultando na clareza da importância de investir, de desempenhar um processo de forma eficiente para facilitar toda a gestão organizacional (melhorar o relacionamento entre trabalhadores, clientes e superiores). É também necessário evitar a distorção da informação e melhorar a informação, com a sintonia dos circuitos, a fim de criar um plano de comunicação estratégica, que auxilie no alcance de resultados e no cumprimento dos objetivos. Segundo Chiavenatto (2004, p. 20) "as organizações são instrumentos sociais através dos quais as pessoas combinam os seus esforços e trabalham juntas para atingir propósitos que isoladamente jamais poderiam alcançar”.

Contudo, para que isso se torne possível a organização precisa propiciar um ambiente favorável à troca, à produtividade, à abertura, à inovação e à criatividade. As barreiras comunicacionais existentes, principalmente nas organizações fechadas, precisam ser quebradas para que o fluxo comunicacional possa correr os meios naturais para resultar nos objetivos guiados pelo planejamento organizacional. O conteúdo da comunicação interna deve estabelecer um canal direto com os colaboradores e seu público de interesse de forma a desenvolver um diálogo contínuo com a finalidade de garantir a total compreensão do todo por parte dos funcionários. Para isso, faz-se necessário conhecer os elementos e os entraves ou obstáculos que interferem na comunicação corporativa. Com base em Bueno (2003, p. 6), 


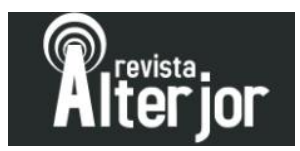

essa área evoluiu para um processo integrado de relacionamento com os públicos de interesse, de tal modo que uma empresa ou entidade moderna não pode prescindir, hoje, dessa articulação. [...] A comunicação é o espelho da cultura empresarial e reflete, necessariamente, os valores das organizações. Se eles caminham para valorizar o profissionalismo, a transparência, a responsabilidade social e participação, a Comunicação se orienta no mesmo sentido.

Como articulador desse meio, os avanços tecnológicos surgiram como um grande parceiro na propagação de mensagens e valores para o público interno de uma organização. As comunicações antes, baseadas nos comunicados, na era do mutismo social, hoje possuem possibilidade de feedback e concedem oportunidade de participação nas decisões que definem os caminhos e rumos seguidos pela organização. A comunicação organizacional é, finalmente, vista e utilizada como meio estratégico com seus públicos preferenciais. Ferramentas da comunicação mercadológica, como relações públicas, marketing direto e propaganda são utilizadas com o público interno, visto na sua concepção de público disseminador. Para Argenti (2006, p. 169), “a comunicação interna no século XXI envolve mais do que memorandos e publicações; envolve desenvolver uma cultura corporativa e ter o potencial de motivar a mudança organizacional".

Do ponto de vista da organização, os investimentos a serem feitos são vantajosos e relevantes. Se analisados de maneira estratégica, a boa fluência da comunicação nas organizações tende a gerar maior produtividade e o desenvolvimento da organização. Contudo, à parte da perspectiva econômica e funcional, Bueno, Silva e Porém (2017) apontam que quando foram iniciados os estudos mais aprofundados em torno da comunicação organizacional, a estrutura funcionalista predominou, utilizando-se fluxogramas e outros canais que buscavam resultados corporativos. Essas ferramentas funcionavam mais como um mecanismo de controle dos gestores, e as organizações acabavam por buscar a simplificação dos processos comunicacionais, que se tornavam superficiais ou receitas prontas das ações tomadas dentro das empresas. Essa simplificação, posteriormente, tornou-se incompatível com o contexto contemporâneo, especialmente por sua visão instrumental e por ignorar as subjetividades e culturas particulares dos colaboradores. Nesse sentido, as empresas, em dado momento, viram- 


\section{Preiejer}

se desafiadas "a repensarem sobre seu modus operandi, priorizando processos que contemplem as mudanças, as ambiguidades, incertezas, aspectos culturais, subjetivos e heterogeneidades" (BUENO; SILVA; PORÉM, 2017, p. 124). A partir desse novo contexto da sociedade e das formas de trabalho,

ao apontar para o caráter estratégico da comunicação organizacional, busca-se refletir sobre esta dimensão de modo a ir além de um viés econômico e administrativo - ao qual comumente é associada. [...] Assim, mais do que compreender esta dimensão como o planejamento de programas fixos pré-estabelecidos para se atingir metas organizacionais, ressalta-se a importância de resgatar o foco no sujeito e na articulação da diversidade sociocultural, proporcionando sinergias, espaço de encontro de conhecimentos e subjetividades (BUENO; SILVA; PORÉM, 2017, p. 127).

Portanto, podemos considerar que a consolidação de um modo de comunicação integrado corrobora para que as ações atreladas à comunicação, quando estabelecidas estrategicamente, voltando-se para um olhar holístico acerca dos colaboradores, e também do público, pautadas no diálogo aberto e dinâmico, tem o poder de desarticular o isolamento de profissionais e de departamentos da organização, oferecendo, conforme indicam Bueno, Silva e Porém (2017), a eliminação de ambiguidades dos diversos cenários internos e externos. A valorização dos sujeitos como seres individuais, culturais e plenos permite que a organização se desenvolva não apenas sob a perspectiva funcional e econômica, e, com a eliminação de planejamentos comunicacionais rígidos e funcionalistas, passam a ser priorizados o bem-estar comum na empresa e o respeito mútuo para com as diversas concepções acerca de problemas, tornando-se possível alcançar melhores soluções e em menor tempo.

\section{CONSIDERAÇÕES FINAIS}

Nosso objetivo foi mostrar a importância do uso estratégico da comunicação organizacional, com foco no ambiente interno, e as visões atuais impulsionadas pelas possibilidades tecnológicas, avaliando como é possível utilizá-la como ferramenta para a compatibilização dos interesses dos empregados e da empresa. Entendemos que tal objetivo foi cumprido, na medida em que discorremos em torno de concepções e 


\section{Ritieior}

conceitos distintos envolvendo a comunicação organizacional, contrapondo, inclusive, a visão funcionalista, e apontando a necessidade da observação da subjetividade de cada colaborador.

Além disso, também ficou demonstrado que as mudanças na direção comunicacional são necessárias para que os interesses sejam equilibrados, as culturas e valores sejam respeitados, gerando uma troca informacional eficaz e que cumpra com o objetivo proposto nas estratégias das organizações, seguindo o planejamento macro da comunicação.

A comunicação unidirecional já não possui mais espaço na sociedade contemporânea. É preciso integrar os públicos. Se antes os funcionários eram vistos como marginalizados (no sentido de estarem à margem), se eram vistos como peças ou como se fossem parte do próprio maquinário das empresas, hoje pode ser decisivo que eles compartilhem suas ideias e façam parte dos processos decisórios.

A comunicação organizacional está mostrando a sua força para ser empregada aos moldes das necessidades e fatores motivacionais distintos. Com isso, o valor da comunicação, mais do que informar, é atrair, é incentivar o bom desempenho quer dos indivíduos que constituem a organização, quer entre as estruturas internas que a suportam.

No começo deste artigo, questionamos: como a comunicação organizacional pode ser utilizada como ferramenta para a compatibilização dos interesses dos empregados e da empresa? Foi possível perceber que a comunicação organizacional é uma ferramenta estratégica para compatibilização desses interesses, e que um dos fatores mais importantes para que esse processo seja, de fato, implementado, é através do estímulo ao diálogo, à troca de informações e de experiências, e à participação de todos os níveis. Especialmente, podemos concluir que é mediante um olhar para os sujeitos como seres completos e imbuídos de uma cultura particular, de emoções e razões peculiares, é mediante o respeito à diversidade de perspectivas que se torna possível otimizar a resolução de problemas dentro das organizações e compatibilizar os interesses.

Revista ALTERJOR

Grupo de Estudos Alterjor: Jornalismo Popular e Alternativo (ECA-USP)

Ano 10 Volume 02 Edição $22 \quad$ Julho- Dezembro de 2020

Avenida Professor Lúcio Martins Rodrig̉ues, 443, Cidade Universitária, São Paulo, CEP: 05508-020 


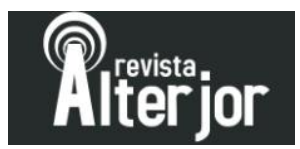

\section{REFERÊNCIAS}

ARGENTI, Paul A. Comunicação Empresarial: a construção da identidade, imagem e reputação. Rio de Janeiro: Elsevier, 2006.

BUENO, W. C. Comunicação Empresarial: Teoria e pesquisa. São Paulo: Monole, 2003.

BUENO, D. A.; SILVA, M. R.; PORÉM, M. E. Comunicação Organizacional, Estratégica e Integrada em Micro e Pequenas Empresas: Estudo Exploratório Sobre Escolas de Idiomas NãoFranqueadas de Bauru/SP. I Congresso Internacional de Mídia e Tecnologia - Unesp, Bauru, Brasil, 04-06 out. 2017. p. 122-135.

CASTELLS, M. A sociedade em rede - a era da informação: economia, sociedade e cultura. São Paulo: Paz e Terra, 1999.

CHIAVENATO, I. Recursos Humanos. São Paulo: Atlas, 2002.

. Introdução à Teoria Geral da Administração. Elsivier Brasil, 2004.

Comportamento Organizacional: A dinâmica do sucesso das organizações. São Paulo: Pioneira Thomson Learning, 2005.

KUNSCH, M. M. K. Planejamento de relações públicas na comunicação integrada. $2^{\mathrm{a}}$ ed. São Paulo: Summus, 2002.

MOLENA, Airton. A Comunicação na gestão de projetos. PRODAM Tecnologia, $3^{\text {a }}$ ed., Ano 2, out./dez. 2009.

MOURÃO, I. Estratégia planejada de comunicação: um novo construto quando se considera a complexidade e a disputa de sentidos. XXXVI Congresso Brasileiro de Ciências da Comunicação, Manaus, 4-7 set. 2013.

MORGAN, G. Imagens da organização. São Paulo: Atlas, 1996.

PANTOJA, A.; et al. Os valores e as relações interpessoais no contexto organizacional. 2013. [online] Disponível em: <http://www.webartigos.com/artigos/os-valores-e-as-relacoesinterpessoais-no-contexto-organizacional/114939/> Acesso em 02 fev. 2020.

RABAÇA, C. A; BARBOSA, G. Dicionário da Comunicação. São Paulo: Ática, 1987.

REIS, M. C.; MARCHIORI, M.; CASALI, A. M. A relação comunicação estratégia no contexto das práticas organizacionais. In MARCHIORI, M. (Org). Comunicação e Organização: reflexões, processos e práticas. São Caetano: Difusão Editora, 2010.

RIBEIRO. J. Comportamento Organizacional. 2008. [online] Disponível em: $<\mathrm{http} / / /$ tecempreende.anje.pt/system/files/items/344/original/ComportamentoOrgan-v11final.pdf > Acesso em 02 fev. 2020.

TORQUATO, G. Comunicação nas Organizações. São Paulo: Summus, 2015. 